\title{
Nova espécie de Geoplana Stimpson (Platyhelminthes, Tricladida, Terricola) do sul do Brasil
}

\author{
Vanessa dos A. Baptista ${ }^{1} \&$ Ana M. Leal-Zanchet ${ }^{1,2}$ \\ ${ }^{1}$ Instituto de Pesquisa de Planárias, Programa de Pós-Graduação em Biologia, Universidade do Vale do Rio dos Sinos. \\ 93022-000 São Leopoldo, Rio Grande do Sul, Brasil. E-mail: zanchet@unisinos.br \\ 2 Pesquisador do CNPq.
}

\begin{abstract}
A new species of Geoplana Stimpson (Platyhelminthes, Tricladida, Terricola) from South Brasil. A new species of Geoplana Stimpson, 1857, registered for the National Forest of São Francisco de Paula, Rio Grande do Sul, Brasil, is described. Geoplana rubidolineata sp. nov. has a characteristic colour pattern, as well as a combination of characters of the internal morphology, which differentiate it from other species presenting a lining in the female atrium with multilayered aspect.
\end{abstract}

KEY WORDS. Geoplaninae, land planarian, morphology, taxonomy.

RESUMO. Descreve-se uma nova espécie de Geoplana Stimpson, 1857 ocorrente na Floresta Nacional de São Francisco de Paula, Rio Grande do Sul, Brasil. Geoplana rubidolineata sp. nov. possui padrão de coloração característico, além de uma combinação de caracteres da morfologia interna, que a diferencia das demais espécies que apresentam epitélio com aparência estratificada revestindo o átrio feminino.

PALAVRAS CHAVE. Geoplaninae, morfologia, planária terrestre, taxonomia.

Geoplaninae é representada atualmente por cerca de 250 espécies, com o gênero Geoplana Stimpson, 1857 incluindo cerca de 108 espécies descritas, 73 delas registradas para o Brasil (Ogren \& Kanakatsu 1990, Carbayo \& Leal-Zanchet 2001, Leal-Zanchet \& Carbayo 2001). Para o Rio Grande do Sul, havia registro de apenas oito espécies desse gênero (Graff 1899, Frokhlich 1959, Ogren et al. 1997), mas estudos recentes, realizados por LEAL-ZANCHET \& CARbayo (2000), registraram a ocorrência de 15 espécies de Geoplana somente para a Floresta Nacional de São Francisco de Paula, sendo uma destas descrita no presente trabalho.

\section{MATERIAL E MÉTODOS}

Os espécimes de Geoplana rubidolineata sp. nov. foram coletados, de forma direta, sob galhos caídos, na Floresta Nacional de São Francisco de Paula - FLONA/FSP, Rio Grande do Sul, Brasil. Esta unidade de conservação, onde predomina floresta ombrófila mista, localiza-se no distrito do Rincão dos Kroeff, entre $29^{\circ} 23^{\prime}-29^{\circ} 27^{\prime} \mathrm{S}$ e $50^{\circ} 23^{\prime}-50^{\circ} 25^{\prime} \mathrm{W}$, ocupando área de aproximadamente 1.607 ha, a uma altitude máxima de cerca de 930 m. A morfologia externa dos espécimes, em vida e após fixação, foi analisada em laboratório, com auxílio de estereomicroscópio. Os exemplares foram mortos com água fervente e fixados com formalina neutra de Lillie 10\% (Romers 1989). Fragmentos contendo: 1) extremidade anterior, 2) uma porção pré-faríngea, 3) faringe e 4) aparelho copulador foram desidratados em série ascendente de álcool etílico e incluídos em paraplasto. Cortes seri- ados sagitais, transversais ou horizontais (5-7 $\mu \mathrm{m}$ de espessura) foram corados com hematoxilina/eosina (HE) e com os tricrômicos de Mallory/Cason ou Masson/Goldner (RomeIs 1989). Os cortes foram analisados ao microscópio óptico e utilizados para estudo da histologia e anatomia, bem como para reconstrução do aparelho copulador e da faringe. As porções remanescentes dos espécimes foram conservadas em álcool 70\%. A musculatura cutânea foi analisada em cortes transversais da região pré-faríngea. A relação espessura da musculatura cutânea: altura do corpo (índice mc:h) foi calculada, a partir de cortes transversais da região pré-faríngea, conforme o método de FroeHLich (1955). A classificação e descrição das células secretoras foi realizada com base na coloração das secreções com o tricrômico Mallory/Cason, tendo sido utilizadas as denominações eritrófilo(a), xantófilo(a) e cianófilo(a), para as células cuja secreção cora-se, respectivamente, em vermelho, laranja e azul. O material-tipo está depositado na Coleção de Helmintos do Museu de Zoologia da Universidade de São Paulo (MZUSP) e no Museu de Zoologia da Universidade do Vale do Rio dos Sinos (MZU).

\section{Geoplana (Geoplana) rubidolineata sp. nov.}

Geoplana sp. 10; Leal-Zanchet \& Carbayo, 2000.

Geoplana sp. 4; Carbayo, Leal-Zanchet \& Vieira, 2001, 2002.

Etimologia. O nome específico refere-se ao padrão estriado e ao tom vermelho-acastanhado do dorso.

Material-tipo. Holótipo. MZUSP PL.171: F. Carbayo, leg. 
11.II.1999 - região pré-faríngea: cortes transversais em oito lâminas; faringe: cortes sagitais em 14 lâminas; aparelho copulador: cortes sagitais em 17 lâminas. Parátipos: MZUSP PL.172: F. Carbayo, leg. 29.IV.1999 - preservado em álcool etílico 70\%; MZU PL.00070: F. Carbayo, leg. 02.IX.1998 - preservado em álcool etílico 70\%; MZU PL.00071: F. Carbayo, leg. 16.XII.1998 - região pré-faríngea: cortes transversais em 4 lâminas; faringe: cortes sagitais em 10 lâminas; aparelho copulador: cortes sagitais em 12 lâminas; MZU PL.00072: F. Carbayo, leg. 25.I.1999 - fragmento anterior contendo os ovários: cortes horizontais em 6 lâminas; região pré-faríngea: cortes transversais em 16 lâminas; faringe: cortes sagitais em 18 lâminas; aparelho copulador: cortes sagitais em 25 lâminas; MZU PL.00073: F. Carbayo, leg. 09.III.1999 - região pré-faríngea: cortes transversais em seis lâminas; faringe: cortes sagitais em 14 lâminas; aparelho copulador: cortes horizontais em 12 lâminas; MZU PL.00074: F. Carbayo, leg. 13.IV.1999 - fragmento anterior contendo os ovários: cortes sagitais em nove lâminas; região pré-faríngea: cortes transversais em quatro lâminas; faringe: cortes sagitais em nove lâminas; aparelho copulador: cortes sagitais em nove lâminas.

Localidade-tipo. São Francisco de Paula, Rio Grande do Sul, Brasil, em áreas de reflorestamento com Araucaria angustifolia (Bert.) Kuntze.

Distribuição. Rio Grande do Sul (São Francisco de Paula) - Brasil.

Diagnose. Dorso com faixa estreita mediana clara margeada por pigmento preto e, de cada lado, uma faixa paramediana acastanhada, uma faixa lateral preta e uma estria sub-lateral marrom-avermelhada; olhos dorsais com halos claros; bordo glandular com quatro tipos de células secretoras; índice mc:h 13-14\%; faringe cilíndrica; esôfago curto; testículos anteriores no mesmo nível transversal dos ovários e os posteriores, até imediatamente antes da faringe; ductos eferentes desembocando lateralmente no terço ental da vesícula prostática; vesícula prostática longa, com porção extrabulbar ampla e porção intrabulbar tubular; átrio masculino longo, pregueado; papila penial cônica e assimétrica; oviductos emergindo dorsalmente do terço posterior dos ovários e ascendendo posteriormente ao gonóporo; ducto glandular comum curto, dorsal ao átrio feminino; vagina ausente; átrio feminino longo com revestimento alto, de aparência estratificada; comprimento do átrio feminino, $70 \%$ a $90 \%$ o do átrio masculino.

Descrição. Morfologia externa. Em vida, apresentam corpo foliáceo alongado, com comprimento máximo de $50 \mathrm{~mm}$, em reptação (Tab. I). Distância da boca e do gonóporo à extremidade anterior variando, respectivamente, de $61 \%$ a $71 \%$ e de $70 \%$ a $86 \%$ do comprimento do corpo (Tab. I). Dorso com faixa mediana clara com largura de $0,5 \mathrm{~mm}$ (ca. 13\% da largura do corpo nos parátipos MZU PL.00070 e MZUSP PL.172), margeada por pigmento preto, seguida, de cada lado, por faixa paramediana acastanhada e faixa lateral preta, ambas com 0,4 mm de largura (ca. 10\% da largura do corpo nos parátipos MZU PL.00070 e MZUSP PL.172), e estria sub-lateral marrom-avermelhada com 0,2 mm de largura (ca. 7\% da largura do corpo nos parátipos MZU PL.00070 e MZUSP PL.172). Cor de fundo do dorso, acinzentada, visível nas margens (Fig. 1). As estrias e faixas iniciam a ca. de $7 \mathrm{~mm}$ da extremidade anterior e convergem em direção à extremidade posterior (Fig. 2). Após fixação, o padrão de coloração se mantém. Ventre bege-claro em vida e após fixação; em vida, extremidade anterior de contorno cinza. Os olhos contornam a extremidade anterior do corpo, marginais e unisseriais até $1,5 \mathrm{~mm}$ da extremidade anterior $(3,8 \%$ e $6,5 \%$ do comprimento do corpo, respectivamente, nos parátipos MZU PL.00070

Tabela I. Medidas dos espécimes-tipo de G. rubidolineata sp. nov. (mm). (-) Não medido, (*) após fixação, (DG) distância do gonóporo à extremidade anterior, (DM) distância da boca à extremidade anterior, (DG \%), (DM\%): DG e DM, respectivamente, em relação ao comprimento do corpo.

\begin{tabular}{|c|c|c|c|c|c|c|c|}
\hline & $\begin{array}{c}\text { Holótipo } \\
\text { MZUSP } \\
\text { PL.171 }\end{array}$ & $\begin{array}{l}\text { Parátipo } \\
\text { MZUSP } \\
\text { PL.172 }\end{array}$ & $\begin{array}{c}\text { Parátipo } \\
\text { MZU } \\
\text { PL.00070 }\end{array}$ & $\begin{array}{c}\text { Parátipo } \\
\text { MZU } \\
\text { PL.00071 }\end{array}$ & $\begin{array}{c}\text { Parátipo } \\
\text { MZU } \\
\text { PL.00072 }\end{array}$ & $\begin{array}{c}\text { Parátipo } \\
\text { MZU } \\
\text { PL.00073 }\end{array}$ & $\begin{array}{c}\text { Parátipo } \\
\text { MZU } \\
\text { PL.00074 }\end{array}$ \\
\hline Comprimento em reptação & 50 & 40 & 35 & 34 & 45 & 42 & 35 \\
\hline Largura em reptação & 3,00 & 2,00 & 2,50 & 2,50 & 2,50 & 2,00 & 1,75 \\
\hline Comprimento em repouso & 25 & 20 & 17 & 25 & 22 & 16 & 18 \\
\hline Largura em repouso & 3,5 & 4,0 & 4,5 & 3,0 & 4,0 & 4,0 & 3,0 \\
\hline Comprimento* & 44 & 19 & 23 & 25 & 28 & 19 & 22 \\
\hline Largura* & 3,5 & 4,0 & 3,0 & 3,0 & 3,5 & 3,0 & 2,0 \\
\hline $\mathrm{DM}^{*}$ & 31 & 13 & 14 & 17 & 19 & 13 & 15 \\
\hline DM\%* & 71 & 68 & 61 & 68 & 68 & 68 & 68 \\
\hline $\mathrm{DG}^{*}$ & 37 & 15 & 16 & 21 & 24 & 15 & 17 \\
\hline DG\%* & 84 & 80 & 70 & 85 & 86 & 79 & 77 \\
\hline Sola Rastejadora* (\%) & - & - & - & - & 83 & 84 & - \\
\hline
\end{tabular}

Revista Brasileira de Zoologia 22 (4): 875-882, dezembro 2005 

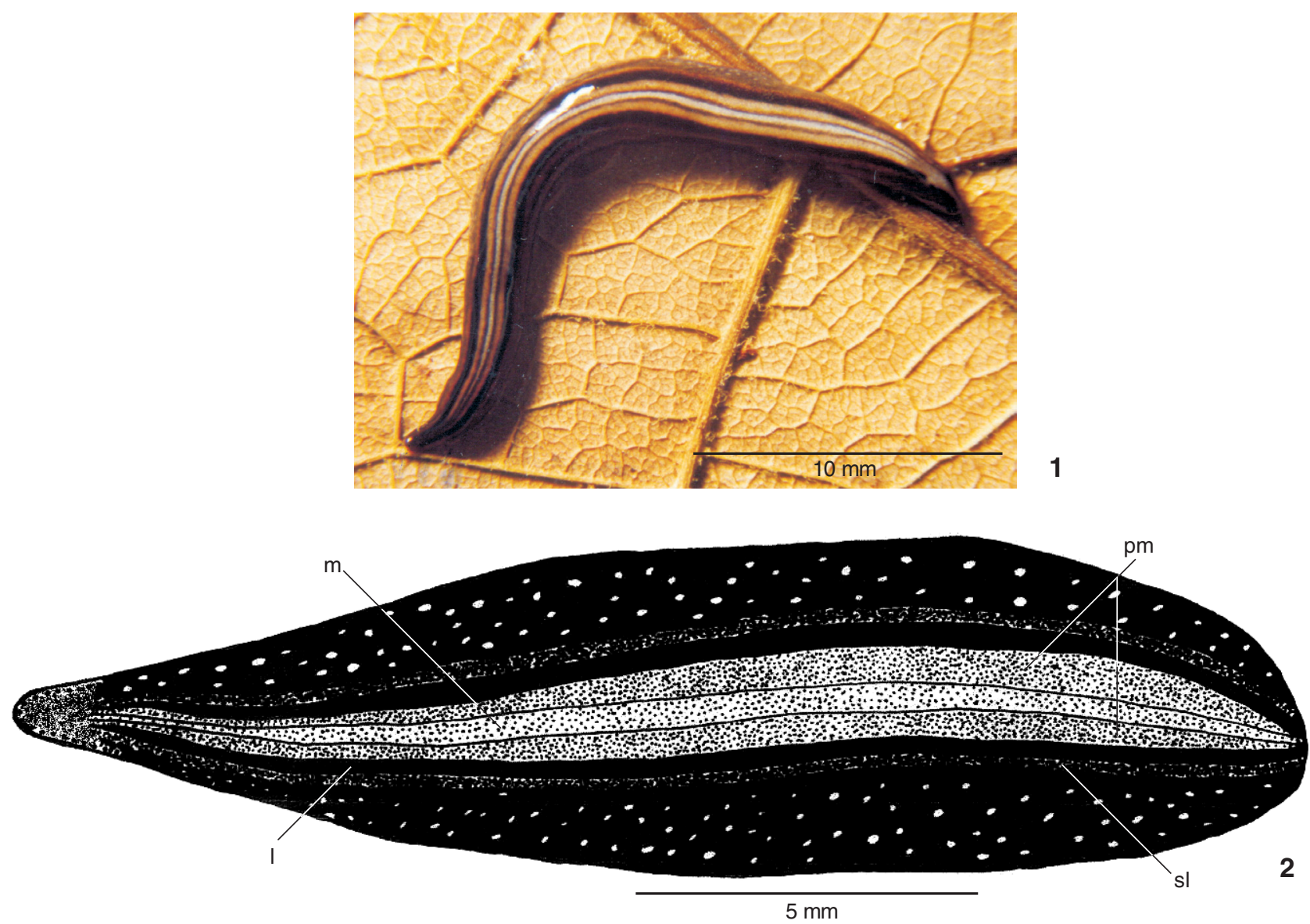

Figura 1. Geoplana rubidolineata sp. nov.: (1) fotografia do parátipo MZU PL.00071, em vida. Notar os halos dos olhos visualizados como pequenas manchas claras (seta); (2) parátipo MZUSP PL.172, representação esquemática da morfologia externa. (I) faixa lateral, (m) faixa mediana, (pm) faixas paramedianas, (sl) estria sub-lateral.

e MZUSP PL.172). Posteriormente, olhos com halos claros invadem o dorso, estendendo-se até a estria sub-lateral, no máximo até $0,5 \mathrm{~mm}$ (25\% da largura do corpo, no parátipo MZUSP PL.172), de cada lado (Fig. 2).

Epiderme e musculatura da região pré-faríngea. Sola rastejadora, mais de $80 \%$ da largura do corpo (Tab. I). A epiderme recebe a desembocadura de células secretoras cianófilas com secreção amorfa, numerosas na sola rastejadora, células xantófilas com secreção granular grossa e células rabidtógenas, com secreção xantófila, as duas últimas abundantes na epiderme dorsal. Adicionalmente, células secretoras eritrófilas, com secreção granular fina, desembocam na epiderme dorsal. Bordo glandular (Fig. 3) constituído por quatro tipos de células secretoras: células eritrófilas com secreção granular fina, células cianófilas com secreção amorfa e dois tipos de células xantófilas, ambas com secreção granular grossa, respectivamente, com coloração laranja e amarelada. Musculatura cutânea constituída por três camadas: camada subepitelial circular, seguida por uma camada diagonal com fibras oblíquas entrecruzadas e uma camada longitudinal, mais espessa, com fibras dispostas em feixes (Tab. II). Índice mc:h, 13 a 14\%.

Faringe cilíndrica (Fig. 4); no holótipo, com as inserções dorsal e ventral no mesmo nível transversal e, nos parátipos MZU PL.00071 e MZU PL.00072, com inserção dorsal algo deslocada posteriormente. Glândulas faringeais, de três tipos, com corpos celulares localizados no mesênquima, principalmente anterior e posteriormente à faringe: células secretoras xantófilas e eritrófilas, ambas com granulação fina, e células cianófilas com secreção amorfa. Musculatura externa da faringe (38 $\mu \mathrm{m}$ de espessura no holótipo) constituída por uma camada longitudinal subepitelial, seguida por outra circular mais desenvolvida, sendo esta última intercalada com algumas fibras longitudinais mais abundantes internamente. Musculatura interna da faringe (50 $\mu \mathrm{m}$ de espessura no holótipo) composta por espessa camada circular contendo fibras longitudinais intercaladas. Em determinados locais, ao longo do comprimento

Revista Brasileira de Zoologia 22 (4): 875-882, dezembro 2005 
Tabela II. Musculatura cutânea na região mediana de um corte transversal da pré-faringe, $(\mu \mathrm{m})$, e proporção entre a altura da musculatura cutânea e a altura do corpo (índice mc:h) de espécimes-tipo de $G$. rubidolineata sp. nov.

\begin{tabular}{lcc}
\hline & $\begin{array}{c}\text { Holótipo } \\
\text { MZUSP PL.171 }\end{array}$ & $\begin{array}{c}\text { Parátipo } \\
\text { MZU PL.00072 }\end{array}$ \\
\hline Circular dorsal & 3 & 5 \\
Oblíqua dorsal & 7 & 6 \\
Longitudinal dorsal & 44 & 31 \\
Dorsal total & 54 & 42 \\
Circular ventral & 4 & 6 \\
Oblíqua ventral & 8 & 6 \\
Longitudinal ventral & 31 & 27 \\
Ventral total & 43 & 39 \\
mc:h (\%) & 13 & 14 \\
\hline
\end{tabular}

da faringe, algumas das fibras longitudinais mais internas ocorrem separadas do restante da camada por mesênquima. Esôfago curto (Fig. 4) com epitélio de revestimento cúbico ciliado e espessa camada muscular subepitelial circular ( $49 \mu \mathrm{m}$ no holótipo) contendo poucas fibras longitudinais intercaladas. Valores do comprimento da faringe, da bolsa faríngea, do esôfago e do deslocamento da inserção dorsal da faringe na tabela III.

Tabela III. Valores do comprimento da faringe, da bolsa faríngea e do esôfago e do deslocamento da inserção dorsal da faringe $(\mathrm{mm})$ de espécimes-tipo de G. rubidolineata sp. nov.

\begin{tabular}{lccc}
\hline & $\begin{array}{c}\text { Holótipo } \\
\text { MZUSP } \\
\text { PL.171 }\end{array}$ & $\begin{array}{c}\text { Parátipo } \\
\text { MZU } \\
\text { PL.00071 }\end{array}$ & $\begin{array}{c}\text { Parátipo } \\
\text { MZU } \\
\text { PL.00072 }\end{array}$ \\
\hline Faringe & 2,1 & 1,5 & 1,5 \\
$\begin{array}{l}\text { Deslocamento da } \\
\text { inserção dorsal }\end{array}$ & 0 & 0,2 & 0,3 \\
$\begin{array}{l}\text { Bolsa faríngea } \\
\text { Esôfago }\end{array}$ & 3,0 & 1,5 & 2,3 \\
\hline
\end{tabular}

Sistema reprodutor (Figs 5-8). Testículos, pré-faringeais, arranjados dorsalmente em uma ou duas fileiras de cada lado do corpo. Os mais anteriores localizados a ca. de $5 \mathrm{~mm}$ e $6 \mathrm{~mm}$ da extremidade anterior do corpo (21\% e $23 \%$ do comprimento do corpo), respectivamente, nos parátipos MZU PL.00074 e MZU PL.00072, e os mais posteriores, até imediatamente antes da faringe. Testículos mais posteriores situados a ca. de $13 \mathrm{~mm}$ e $16 \mathrm{~mm}$ da extremidade anterior (53\% e 57\% do comprimento do corpo), respectivamente, nos parátipos MZU PL.00074 e MZU PL.00072. Ductos eferentes desembocam lateralmente no terço ental da vesícula prostática (Figs 7, 8).

Vesícula prostática com porção extrabulbar longa e am- pla e porção intrabulbar tubular (Tab. IV, Figs 7, 8). Extremidade ental da vesícula a ca. de $2 \mathrm{~mm}$ da extremidade posterior da bolsa faríngea. Porção intrabulbar da vesícula continua-se com o ducto ejaculatório, que atravessa a papila penial e desemboca no seu ápice, algo deslocado ventralmente (Fig. 5). Átrio masculino longo e pregueado (Tab. IV, Figs 6-8), apresentando a metade ental ou os dois terços entais ocupados pela papila penial cônica e assimétrica.

Vesícula e ducto ejaculatório revestidos por epitélio cilíndrico ciliado, diminuindo gradativamente de altura no ducto, onde desembocam células secretoras eritrófilas com granulação fina, ocorrendo em menor quantidade na porção intrabulbar da vesícula. No ducto ejaculatório desembocam, adicionalmente, células secretoras cianófilas com secreção amorfa. Muscularis da porção extrabulbar bem desenvolvida ( $49 \mu \mathrm{m}$ de espessura no holótipo), constituída por fibras circulares e longitudinais intercaladas; muscularis da porção intrabulbar da vesícula $(12 \mathrm{~mm}$ de comprimento no holótipo) e do ducto ejaculatório predominantemente circular com poucas fibras longitudinais intercaladas.

Papila penial revestida por epitélio cilíndrico, diminuindo gradativamente de altura em direção ao ápice da papila, através do qual desembocam células secretoras eritrófilas com granulação grossa e células xantófilas com grânulos finos. Átrio masculino revestido por epitélio cúbico a cilíndrico baixo, através do qual desembocam células secretoras eritrófilas com granulação fina e cianófilas com secreção amorfa. Muscularis da papila penial e do átrio masculino constituídas por camada subepitelial circular e camada longitudinal subjacente; na papila penial, algo mais espessas na superfície dorsal do que na ventral e, no átrio, ca. de 20 vezes mais espessas na parede dorsal do que na ventral.

Ovários localizados aproximadamente no mesmo nível transversal dos testículos mais anteriores, situando-se a uma distância média de ca. de $6 \mathrm{~mm}$ da extremidade anterior (cerca de 23\% do comprimento do corpo), nos parátipos MZU PL.00072 e MZU PL.00074. Os ovários medem 0,3 mm no sentido ânteroposterior e 0,06 mm no eixo lateral no parátipo MZU PL.00074. Os oviductos emergem dorsalmente do terço posterior dos ovários. Posteriormente ao gonóporo direcionam-se para o dorso e para o plano mediano, unindo-se para formar um ducto glandular comum muito curto. Este dirige-se caudalmente e desemboca diretamente na extremidade posterior do átrio feminino que se apresenta oval-alongado, com luz estreita e irregular, com comprimento correspondente a 70\%, no parátipo MZU PL.00071 e no holótipo, e 90\%, no parátipo MZU PL.00072, o do átrio masculino. Vagina ausente. Canal do gonóporo inclinado anteriormente (Figs. 6, 8).

Oviductos e ducto glandular comum revestidos por epitélio ciliado, cúbico a cilíndrico baixo, com desembocadura de glândulas da casca na porção ascendente dos oviductos e no ducto glandular comum. Muscularis dos oviductos predominantemente circular; no ducto glandular comum constituída por fibras circulares e longitudinais intercaladas. Átrio femini- 

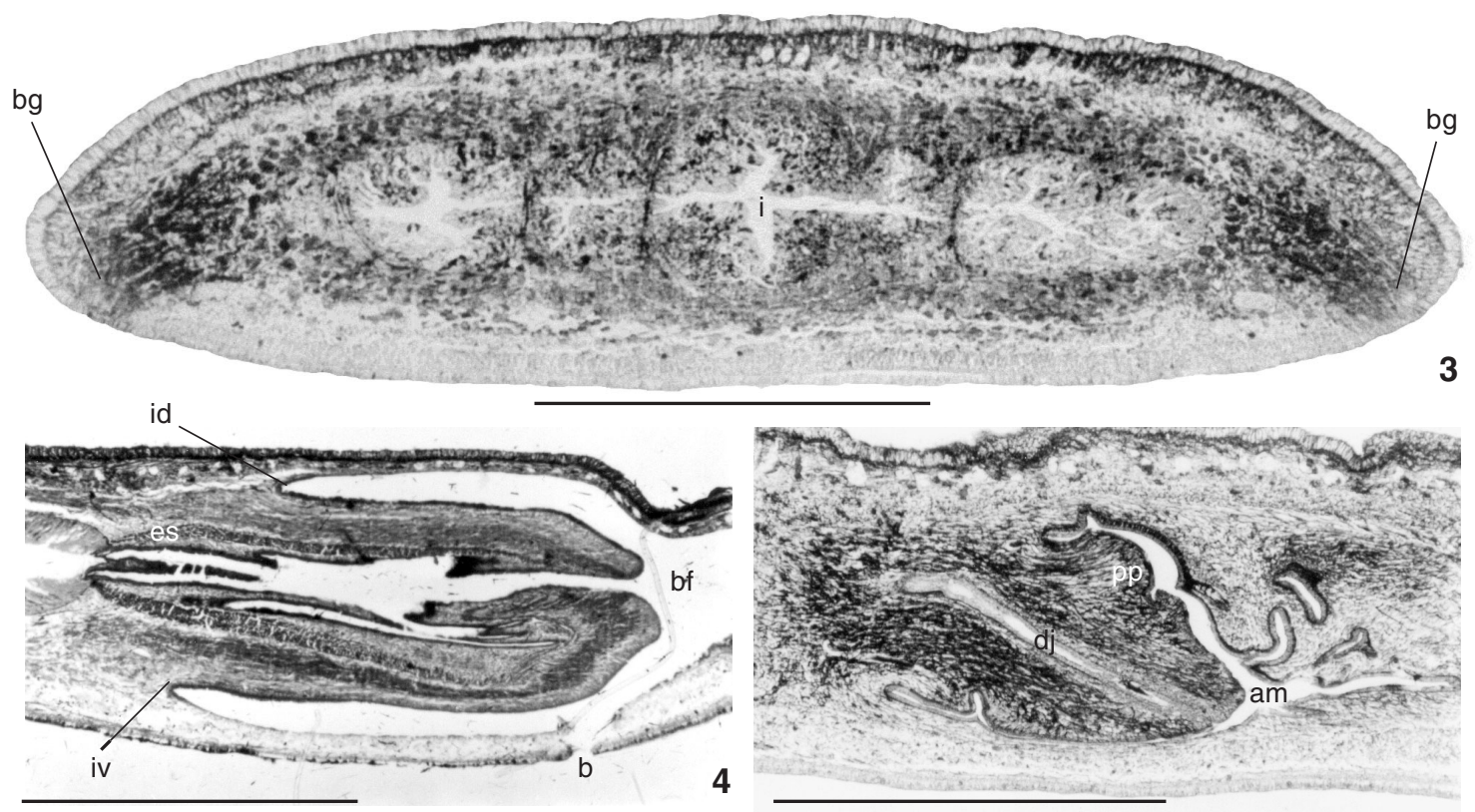

Figuras 3-5. Geoplana rubidolineata sp. nov.: (3) holótipo, corte transversal da região pré-faríngea; (4) parátipo MZU PL.00072, corte sagital da faringe; (5) holótipo, corte para-sagital da região ental do átrio masculino. (am) Átrio masculino, (b) boca, (bf) bolsa faríngea, (bg) bordo glandular, (dj) ducto ejaculatório, (es) esôfago, (i) intestino, (id) inserção dorsal, (iv) inserção ventral, (pp) papila penial. Barra: $1 \mathrm{~mm}$.

Tabela IV. Comprimento dos órgãos do aparelho copulador ( $\mathrm{mm}$ ) de espécimes-tipo de G. rubidolineata sp. nov. (-) Não medido.

\begin{tabular}{lccc}
\hline & Holótipo (MZUSP PL.171) & Parátipo (MZU PL.00071) & Parátipo (MZU PL.00072) \\
\hline Átrio feminino & 1,10 & 0,70 & 0,90 \\
Átrio masculino & 1,60 & 1,00 & 1,00 \\
Papila penial & 0,90 & 0,50 & 0,70 \\
Porção extrabulbar da vesícula & 0,50 & 0,70 & 0,50 \\
Porção intrabulbar da vesícula & 0,10 & 0,10 & 0,05 \\
Ducto glandular comum & 0,02 & - & 0,03 \\
Distância vesícula/bolsa faríngea & 1,70 & - & 1,60 \\
\hline
\end{tabular}

no revestido por epitélio muito alto, com aparência estratificada, constituído por uma massa compacta de células, reduzindo a cavidade atrial a uma fenda irregular. Através do epitélio atrial desembocam células secretoras cianófilas e xantófilas, ambas com secreção amorfa. Muscularis constituída por fibras circulares e longitudinais intercaladas.

Capa muscular comum pouco desenvolvida, constituída principalmente por fibras longitudinais, além de escassas fibras oblíquas e transversais.

Comentários. Vitelários bem desenvolvidos nos espécimes analisados. No holótipo, espermatozóides e secreção xantófila acumulam-se na luz do átrio feminino.

\section{DISCUSSÃO}

Dentre as 108 espécies incluídas no gênero Geoplana, 23 apresentam o átrio feminino revestido por epitélio com aparência estratificada (Tab. V). Esse carácter não indica afinidade filogenética, mas tem um importante valor diagnóstico, ao nível de espécie, facilitando a comparação entre as espécies. Assim, uma análise comparativa entre G. rubidolineata sp. nov. e as 23 espécies acima referidas (Tab. V) indica que apenas duas, Geoplana gaucha Froehlich, 1959 e G. multicolor Graff, 1899, possuem padrão de coloração semelhante ao de G. rubidolineata sp. nov. (Tab. V), diferenciando-se principalmente por apre-

Revista Brasileira de Zoologia 22 (4): 875-882, dezembro 2005 

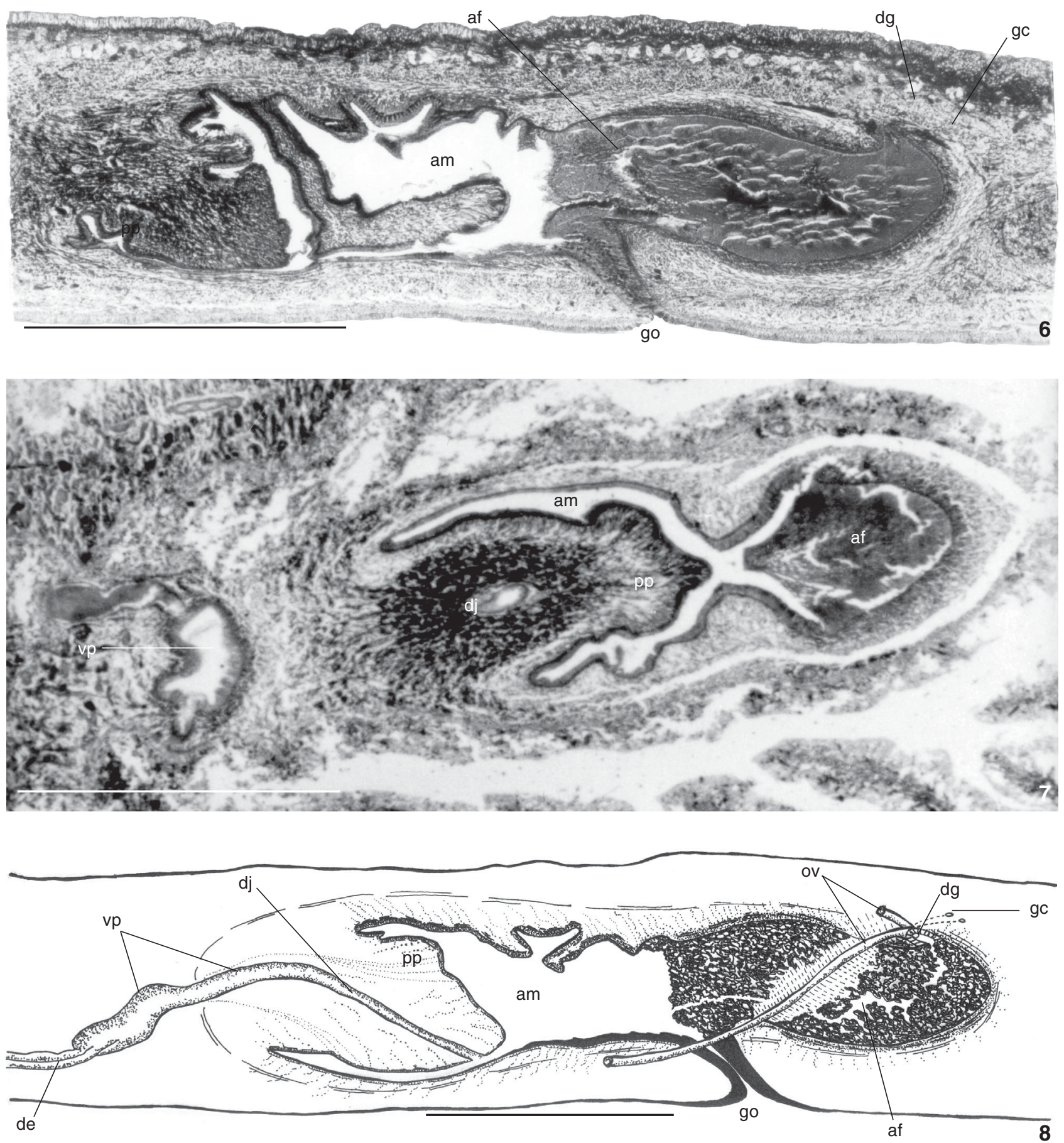

Figuras 6-8. Geoplana rubidolineata sp. nov.: (6) holótipo, corte sagital do aparelho copulador, onde ducto ejaculatório e vesícula não são visíveis; (7) parátipo MZU PL.00073, corte horizontal do aparelho copulador, (8) holótipo, reconstrução do aparelho copulador a partir de cortes sagitais. (af) Átrio feminino, (am) átrio masculino, (de) ducto eferente, (dg) ducto glandular comum, (dj) ducto ejaculatório, (gc) glândulas da casca, (go) gonóporo, (id) inserção dorsal, (ov) oviductos, (pp) papila penial, (vp) vesícula prostática. Setas: desembocadura dos ductos eferentes na vesícula prostática. As fissuras visualizadas no epitélio de revestimento do átrio feminino, nas figuras 6 e 7, são artefatos do processamento histológico. Barra: 1 mm.

Revista Brasileira de Zoologia 22 (4): 875-882, dezembro 2005 
sentarem um número menor de estrias do que G. rubidolineata sp. nov. As demais espécies apresentam um padrão de coloração bastante distinto de G. rubidolineata sp. nov. Ainda, quanto à morfologia externa, 15 das espécies acima referidas também diferenciam-se G. rubidolineata sp. nov. por apresentarem olhos exclusivamente marginais ou, quando com olhos dorsais, por inexistência de halos (Tab. V).

Quanto ao tipo de faringe, G. rubidolineata sp. nov. assemelha-se à maioria das 23 espécies acima referidas, apresentando faringe cilíndrica, com exceção de G. crioula Froehlich, 1955, que apresenta faringe campanuliforme.

Quanto à morfologia do aparelho copulador, das 23 espécies comparadas com $G$. rubidolineata sp. nov., nove apresentam luz muito ampla no átrio feminino, diferenciando-se de $G$. rubidolineata sp. nov., cujo epitélio de revestimento, com aparência estratificada, preenche praticamente toda a cavidade atrial.

Comparando G. rubidolineata sp. nov. com as espécies com luz do átrio feminino reduzida, verifica-se que $G$. rubidolineata sp. nov. diferencia-se de muitas dessas espécies pela vesícula não bifurcada ou pela longa porção extrabulbar da vesícula. Assim, G. caapora Froehlich, 1957, G. carrierei Graff, 1897, G. crawfordi Beauchamp, 1939, G. gaucha e G. multicolor diferenciam-se por apresentarem vesícula prostática bifurcada. G. crioula possui vesícula com curta bifurcação ental e G. goettei Schirch, 1929, vesícula subdividida em duas câmaras unidas por um canal (Tab. V), diferentemente de G. rubidolineata sp. nov. Geoplana franciscana Leal-Zanchet \& Carbayo, 2001, G. incognita Riester, 1938, G. phocaica Marcus, 1951, G. preta Riester, 1938, G. prudhoei Kawakatsu et al. 2002, G. saima Bois-Reymond Marcus, 1951 e G. tapira Froehlich, 1957 apresentam vesícula prostática não bifurcada, como em G. rubidolineata sp. nov. G. prudhoei diferencia-se por apresentar vesícula exclusivamente intrabulbar, de forma tubular e espiralada, e G. incognita, por apresentar vesícula prostática com curta porção extrabulbar, de forma esférica. G. phocaica e G. saima apresentam vesícula com porção ental direcionada para o ventre e porção ectal espiralada; G. tapira, vesícula direcionada para o ventre; G. preta, vesícula de forma esférica. Em G. franciscana a forma da

Tabela V. Comparação entre G. rubidolineata sp. nov. e outras espécies de Geoplana com átrio feminino revestido por epitélio de aparência estratificada. (AF) Átrio feminino, (+) presente, $(-)$ ausente, $\left(+^{*}\right)$ vesícula com câmaras anterior e posterior unidas por canal, ([+]) vesícula principalmente ímpar com curta bifurcação ental; ([-]) olhos dorsais sem halos, $\left(^{*}\right)$ dorso com faixa mediana e estrias laterais.

\begin{tabular}{|c|c|c|c|c|c|c|}
\hline & $\begin{array}{l}\text { Padrão de } \\
\text { coloração* }\end{array}$ & $\begin{array}{c}\text { Olhos dorsais } \\
\text { com halos }\end{array}$ & $\begin{array}{l}\text { Faringe } \\
\text { cilíndrica }\end{array}$ & $\begin{array}{c}\text { Vesícula } \\
\text { extrabulbar }\end{array}$ & Vesícula ímpar & $\begin{array}{l}\text { AF com luz } \\
\text { reduzida }\end{array}$ \\
\hline G. rubidolineata sp. nov. & + & + & + & + & + & + \\
\hline G. beckeri Froehlich, 1959 & - & {$[-]$} & + & + & {$[+]$} & - \\
\hline G. caapora Froehlich, 1957 & - & + & + & + & - & + \\
\hline G. carrierei Graff, 1897 & - & + & + & + & - & + \\
\hline G. chiuna E.M. Froehlich, 1955 & - & {$[-]$} & + & - & {$[+]$} & - \\
\hline G. crawfordi de Beauchamp, 1939 & - & {$[-]$} & + & - & - & + \\
\hline G. crioula E.M. Froehlich, 1955 & - & + & - & + & {$[+]$} & + \\
\hline G. fragai Froehlich, 1955 & - & - & + & - & + & - \\
\hline G. franciscana Leal-Zanchet \& Carbayo, 2001 & - & + & + & + & + & + \\
\hline G. gaucha Froehlich, 1959 & + & + & + & + & - & + \\
\hline G. goettei Schirch, 1929 & - & - & + & + & $+^{*}$ & + \\
\hline G. incognita Riester, 1938 & - & {$[-]$} & + & + & + & + \\
\hline G. josefi Carbayo \& Leal-Zanchet, 2001 & - & {$[-]$} & + & + & - & - \\
\hline G. matuta E.M. Froehlich, 1955 & - & - & + & - & {$[+]$} & - \\
\hline G. mirim E.M. Froehlich, 1972 & - & + & + & + & - & - \\
\hline G. multicolor Graff, 1899 & + & + & + & + & - & + \\
\hline G. phocaica Marcus, 1951 & - & - & + & + & + & + \\
\hline G. placilla E.M. Froehlich, 1978 & - & + & + & + & + & - \\
\hline G. preta Riester, 1938 & - & - & + & + & + & + \\
\hline G. prudhoei Kawakatsu et al., 2002 & - & {$[-]$} & + & - & + & + \\
\hline G. saima du Bois-Reymond Marcus, 1951 & - & - & + & + & + & + \\
\hline G. suva Froehlich, 1959 & - & - & + & + & $+^{*}$ & - \\
\hline G. tapira Froehlich, 1957 & - & {$[-]$} & + & + & + & + \\
\hline G. tuxaua E.M. Froehlich, 1955 & - & - & + & - & {$[+]$} & - \\
\hline
\end{tabular}


vesícula é similar a de G. rubidolineata sp. nov. Quanto à desembocadura dos ductos eferentes na vesícula prostática, caráter importante de ser analisado juntamente com a forma e posição da vesícula, nota-se que, dessas espécies que apresentam vesícula extrabulbar e indivisa, em G. incognita, G. phocaica, G. preta e $G$. franciscana, os ductos eferentes desembocam, similarmente a $G$. rubidolineata sp. nov., na parede lateral da vesícula.

Ainda em relação à porção masculina do aparelho copulador, é importante destacar que G. rubidolineata sp. nov. possui átrio masculino longo e pregueado e papila penial ocupando apenas a metade ou dois terços entais do átrio masculino, características estas que a diferencia das espécies acima referidas, excetuando G. phocaica.

Adicionalmente, caracteres dos órgãos femininos do aparelho copulador, tais como a orientação do eixo principal do átrio feminino e a extensão da vagina e do ducto glandular comum, podem auxiliar na diferenciação de G. rubidolineata sp. nov. Assim, a orientação do eixo principal do átrio feminino é horizontal em G. rubidolineata sp. nov., como na maioria das espécies de Geoplana, mas vertical em G. saima e tende à verticalidade em G. caapora, G. multicolor, G. prudhoei e G. incognita.

Quanto à extensão comparativa da vagina ( = canal feminino) e do ducto glandular comum em relação ao comprimento do átrio feminino, verifica-se que, similarmente a $G$. rubidolineata sp. nov., G. crawfordi, G. crioula, G. gaucha e $G$. saima não apresentam um divertículo ental ( = vagina) do átrio feminino e possuem ducto glandular comum muito curto. $G$. tapira não possui vagina, mas o ducto glandular comum é relativamente longo, similarmente a G. prudhoei. Já G. caapora, G. goettei e G. multicolor diferenciam-se por não apresentarem ducto glandular comum, enquanto $G$. carrierei, G. franciscana, $G$. incognita, G. phocaica e G. preta possuem ducto glandular comum relativamente mais longo do que em G. rubidolineata sp. nov., além de apresentarem vagina.

Assim, a combinação de caracteres apresentada por $G$. rubidolineata sp. nov. a diferencia das demais espécies descritas para o gênero.

\section{AGRADECIMENTOS}

Ao $\mathrm{CNPq}$, as bolsas de produtividade em pesquisa e de iniciação científica (PIBIC) concedidas, respectivamente, a Ana Maria Leal-Zanchet e Vanessa dos Anjos Baptista. Ao Instituto Brasileiro do Meio Ambiente e dos Recursos Naturais Renováveis - IBAMA, a autorização para o desenvolvimento de pesquisas na Floresta Nacional de São Francisco de Paula. Ao Dr. Fernando Carbayo, a coleta dos espécimes e a confecção da foto utilizada na figura 1. Às laboratoristas Letícia A. Guterres e Teresinha H. Oliveira, respectivamente, o auxílio na confecção das prepara- ções histológicas e na confecção das fotos. À Dra Eudóxia Froehlich, pelas sugestões realizadas numa versão preliminar do manuscrito.

\section{REFERÊNCIAS BIBLIOGRÁFICAS}

Carbayo, F. \& A.M. Leal-Zanchet. 2001. A new species of terrestrial planarian (Platyhelminthes, Tricladida: Terricola) from south Brazil. Brazilian Journal of Biology, São Carlos, 61 (3): 437447.

Carbayo, F.; A.M. Leal-Zanchet \& E.M. Vieira 2001. Land planarians (Platyhelminthes: Tricladida: Terricola) as indicators of maninduced disturbance in a South Brazilian rainforest. Belgian Journal of Zoology, Bruxelas, 131 (Suppl.): 223-224.

Carbayo, F.; A.M. Leal-Zanchet \& E.M. Vieira. 2002. Terrestrial flatworm (Platyhelminthes: Tricladida: Terricola) diversity vs. man-induced disturbance in an ombrophilous forest from Southern Brazil. Biodiversity and Conservation, Dordrecht, 11: 1091-1104.

Froehlich, C.G. 1959. On geoplanids from Brazil. Boletim da Faculdade de Filosofia, Ciências e Letras da Universidade de São Paulo, Série Zoologia, São Paulo, 22: 201-265.

Froenlich, E.M. 1955. Sôbre espécies brasileiras do gênero Geoplana. Boletim da Faculdade de Filosofia, Ciências e Letras da Universidade de São Paulo, Série Zoologia, São Paulo, 19: 289-369.

GrafF, L. 1899. Monographie der Turbellarien: II. Tricladida Terricola. Leipzig, Engelmann, 574p.

Leal-Zanchet, A.M. \& F. Carbayo. 2000. Fauna de planárias terrestres (Platyhelminthes, Tricladida, Terricola) da Floresta Nacional de São Francisco de Paula, RS, Brasil: uma análise preliminar. Acta Biologica Leopoldensia, São Leopoldo, 22 (1): $19-25$.

Leal-Zanchet A.M. \& F. Carbayo. 2001. Two new species of Geoplanidae (Platyhelminthes, Tricladida, Terricola) from Brazil. Journal of Zoology, London, 253: 433-446.

Ogren, R.E. \& M. KaWAKatsu. 1990. Index to the species of the family Geoplanidae (Turbellaria, Tricladida, Terricola). Part I: Geoplaninae. Bulletin of the Fuji Women's College, Sapporo, 28 Serie II: 79-166.

Ogren, R.E.; M. Kawakatsu \& E.M. Froehlich. 1997. Additions and corrections of the previous land planarian indices of the world (Turbellaria, Seriata, Tricladida, Terricola) Addendum IV. Geographic locus index: Bipaliidae; Rhynchodemidae (Rhynchodeminae; Microplaninae); Geoplanidae (Geoplaninae; Caenplaninae; Pematoplaninae). Bulletin of the Fuji Women's College, Sapporo, 35 Serie II: 63-103.

RomeIs, B. 1989. Mikroskopische Technik. München, Urban und Schwarzenberg. 697p.

Recebido em 06.XII.2004; aceito em 30.IX.2005. 